\title{
Hematological and cytochemical characteristics of peripheral blood cells in the argus snakehead (Ophiocephalus argus Cantor)
}

\author{
Xue Wang ${ }^{1}$, Jie Zheng Wu ${ }^{1}$, Mei Sheng Wu ${ }^{1}$, Xian Xian Chen ${ }^{1}$, Hanif Misbah ${ }^{2}$, Zhou Sheng Zhang ${ }^{\text {Corresp. } 1}$ \\ ${ }^{1}$ College of Life Sciences, Anhui Normal University, Wuhu, China \\ College of Life Sciences, Anhui Normal University, Faisalabad, Pakistan \\ Corresponding Author: Zhou Sheng Zhang \\ Email address: szzhang@mail.ahnu.edu.cn
}

Background. The argus snakehead (Ophiocephalus argus Cantor) is a highly nutritious, freshwater, cultured bony fish with a high economic value. The health of the fish is closely related to its blood cells, which are critical for oxygen transport, natural defense, and immunity. We investigated the morphometry, microstructure, and cytochemical characteristics of the peripheral blood cells of $O$. argus. Our results may provide the basic reference values needed to monitor the health of this fish for largescale cultivation.

Methods. The number of blood cells in 0 . argus were counted on a hemocytometer and their size was measured using a micrometer under light microscope. The morphology and classification of the blood cells were studied using Wright's staining and the cytochemical characteristics were studied using seven chemical stains including peroxidase (POX), Sudan black B (SBB), periodic acid-Schiff (PAS), acid phosphatase (ACP), alkaline phosphatase (ALP), chloroacetic acid AS-D naphthol esterase (AS-D), and $\alpha$ naphthol acetate esterase ( $\alpha-\mathrm{NAE})$.

Results. The peripheral blood cells in 0 . argus can be classified as erythrocytes, leukocytes, and thrombocytes; of which, females had 2.9597 million $/ \mathrm{mm}^{3}, 88,400 / \mathrm{mm}^{3}$, and $43,600 / \mathrm{mm}^{3}$, respectively, and males had 3.0105 million $/ \mathrm{mm}^{3}, 105,500 / \mathrm{mm}^{3}$, and $34,000 / \mathrm{mm}^{3}$, respectively. Leukocytes consisted of neutrophils, monocytes, large lymphocytes, and small lymphocytes. Eosinophils and basophils were not found. Monocytes were the most numerous leukocytes identified, followed by neutrophils and small lymphocytes, while large lymphocytes were the least frequently identified. Cytochemical staining showed that erythrocytes were only positive for PAS staining. Neutrophils were strongly positive for POX, SBB, and ACP, and positive for all the other cytochemical stains. Monocytes were positive for PAS and $\alpha-N A E$ and were weakly positive for ACP and AS-D staining. Large lymphocytes were positive for PAS and were weakly positive for ALP, AS-D, and $\alpha$-NAE staining. Small lymphocytes were positive for PAS and weakly positive for AS-D and $\alpha$-NAE staining. Thrombocytes were positive for PAS and were weakly positive for $A C P$ and AS-D, but negative for the remaining cytochemical stains. The morphology of peripheral blood cells in $O$. argus was generally similar to that of other fish species, while the cytochemical staining patterns showed clear species specificity. 
1 Hematological and cytochemical characteristics of peripheral blood cells in the argus snakehead 2 (Ophiocephalus argus Cantor)

3 Xue Wang, Zhengjie Wu, Shengmei Wu, Xianxian Chen, Misbah Hanif, Shengzhou Zhang

4 Key Laboratory for Conservation and Use of Important Biological Resources of Anhui Province, College 5 of Life Sciences, Anhui Normal University, Wuhu, Anhui, China

6 Corresponding author:

$7 \quad$ Shengzhou Zhang

8 College of Life Sciences, Anhui Normal University, 1 Beijing East Road, Wuhu, Anhui Province 241000,

9 People's Republic of China

10 Email: $\underline{\text { szzhang@mail.ahnu.edu.cn }}$ 
20 Abstract

21 Background. The argus snakehead (Ophiocephalus argus Cantor) is a highly nutritious,

22 freshwater, cultured bony fish with a high economic value. The health of the fish is closely

23 related to its blood cells, which are critical for oxygen transport, natural defense, and immunity.

24 We investigated the morphometry, microstructure, and cytochemical characteristics of the

25 peripheral blood cells of $O$. argus. Our results may provide the basic reference values needed to

26 monitor the health of this fish for large-scale cultivation.

27 Methods. The number of blood cells in O. argus were counted on a hemocytometer and their

28 size was measured using a micrometer under light microscope. The morphology and

29 classification of the blood cells were studied using Wright's staining and the cytochemical characteristics were studied using seven chemical stains including peroxidase (POX), Sudan black B (SBB), periodic acid-Schiff (PAS), acid phosphatase (ACP), alkaline phosphatase (ALP), chloroacetic acid AS-D naphthol esterase (AS-D), and $\alpha$-naphthol acetate esterase ( $\alpha$-NAE).

Results. The peripheral blood cells in O. argus can be classified as erythrocytes, leukocytes, and thrombocytes; of which, females had 2.9597 million $/ \mathrm{mm}^{3}, 88,400 / \mathrm{mm}^{3}$, and $43,600 / \mathrm{mm}^{3}$, respectively, and males had 3.0105 million $/ \mathrm{mm}^{3}, 105,500 / \mathrm{mm}^{3}$, and $34,000 / \mathrm{mm}^{3}$, respectively. Leukocytes consisted of neutrophils, monocytes, large lymphocytes, and small lymphocytes. Eosinophils and basophils were not found. Monocytes were the most numerous leukocytes identified, followed by neutrophils and small lymphocytes, while large lymphocytes were the least frequently identified. Cytochemical staining showed that erythrocytes were only positive 
40 for PAS staining. Neutrophils were strongly positive for POX, SBB, and ACP, and positive for

41 all the other cytochemical stains. Monocytes were positive for PAS and $\alpha$-NAE and were weakly

42 positive for ACP and AS-D staining. Large lymphocytes were positive for PAS and were weakly

43 positive for ALP, AS-D, and $\alpha$-NAE staining. Small lymphocytes were positive for PAS and

44 weakly positive for AS-D and $\alpha$-NAE staining. Thrombocytes were positive for PAS and were

45 weakly positive for ACP and AS-D, but negative for the remaining cytochemical stains. The

46 morphology of peripheral blood cells in O. argus was generally similar to that of other fish

47 species, while the cytochemical staining patterns showed clear species specificity.

\section{Introduction}

Vertebrate blood consists of plasma and blood cells. Fish blood cells can be classified as erythrocytes, leukocytes, and thrombocytes, and are vital to the body for gas transportation, immune defense, and coagulation, respectively (Chen et al., 2019b; Palmer et al., 2015). Blood cells are very sensitive to changes in internal physiological conditions and external stimuli (Palmer et al., 2015). Variations in blood cell counts, morphology, and various intracellular functional components can be used as direct markers to determine the health status of fish (Fang et al., 2014; Ishikawa, Ranzani-Paiva \& Lombardi, 2008). 
60 the function and physiological state of blood cells and cell lineages (Massar et al., 2012; Shigdar,

61 Harford \& Ward, 2009). A number of studies have been conducted on the classification,

62 microstructure, and cytochemical characteristics of peripheral blood cells in fish, especially

63 commercially cultured fish. Tripathi, Latimer \& Burnley (2004) determined the hematological

64 reference intervals for koi (Cyprinus carpio), including blood cell morphology, cytochemistry,

65 and ultrastructure. Tavares-Dias \& Moraes (2006) described the morphology, cytochemistry, and

66 ultrastructure of thrombocytes and leukocytes in neotropical fish (Brycon orbignyanus). Tavares-

67 Dias (2006) studied the morphology and cytochemistry of erythrocytes, thrombocytes, and

68 leukocytes in four freshwater teleosts: big head carp (Aristichthys nobilis), oscar (Astrootus

69 ocellatus), traíra (Hoplias malabarus), and lambari (Astyanax bimaculatus). Fang et al. (2014)

70 observed the morphology and cytochemistry of peripheral blood cells in Schizothorax prenanti

71 by light and electron microscopy. Bianchi et al. (2014) described the cell morphology and

72 cytochemical characteristics of a native South America catfish (Sorubim lima). Zheng et al.

73 (2016) investigated the ultrastructure and cytochemical properties of the peripheral blood cells of

74 the piebald naked carp (Gymnocypris eckloni) by transmission electron microscopy. Zhang et al.

75 (2019) compared the microstructure and cytochemical characteristics of peripheral blood cells in

76 the crucian carp (Carassius auratus) and grass carp (Ctenpharyngodon idellus). These studies

77 indicated that the major groups and micromorphology of peripheral blood cells in different fish

78 were generally similar. However, there were obvious species-specific differences in the

79 leukocytes, the proportion of various leukocyte types, and the cytochemical characteristics of

80 blood cells. 
The argus snakehead (Ophiocephalus argus Cantor) belongs to the family Channidae,

82

83

84

perciformes, and is commonly found in the Yangtze River basin and the lower Yellow River in China, as well as in various river systems in Korea, Japan, and Russia (Courtenay \& Williams, 2004). O. argus is a very popular, nutritious, economically-farmed freshwater fish (Xiao et al., 2017). In China, the annual production of $O$. argus is about 510,000 tons (worth approximately

1.6 billion US dollars) (Sagada et al., 2017). The incidence of diseases in $O$. argus has increased as cultivation has increased (Xu et al., 2017). Fish hematology is one diagnostic tool that can provide useful information in guiding treatment options (Grant, 2015). However, the hematology and cytochemistry of peripheral blood cells in $O$. argus has not been well-studied. We investigated the number, microstructure, and cytochemical characteristics of peripheral blood cells in $O$. argus using cell counts, Wright's staining, and cytochemical methods under a light microscope. Our results may improve the understanding of fish hematology, provide a reference for monitoring the health of artificially-bred $O$. argus, and provide basic information for further study of the physiology and immunology of this species.

\section{Materials \& Methods}

\section{Animals and blood smear preparation}

Thirty healthy adult $O$. argus specimens were selected (15 males and 15 females), with an average body length of 30.56-42.78 $\mathrm{cm}$ and weight of 960.20-1850.32 g. All fish were obtained from a local Wuhu aquaculture farm between May and September, 2019. Blood samples were 
101

102

103

104

105

106

107

collected by caudal vein puncture, and about $2 \mathrm{ml}$ of blood was taken from each fish using a sterile $5 \mathrm{ml}$ syringe and $22 \mathrm{G}$ needle. $\mathrm{K}_{2}$-EDTA was used as an anticoagulant to avoid blood coagulation and blood smears were prepared immediately after blood collection. This work was approved by the ethics committee of Anhui Normal University (permit no. 20190312). Fish handling and sampling techniques were carried out in accordance with standard vertebrate procedures and veterinary practices and in accordance with national and provincial guidelines.

\section{Wright's staining}

The prepared blood smears were air-dried at room temperature and treated with Wright's reagent according to the guidelines by Hefei Tianda Diagnostic Reagent Co., Ltd. (Hefei, China). The blood smears were placed in a box containing a parallel support frame and little water, stained with Wright's A solution for $1 \mathrm{~min}$ at room temperature, and treated with Wright's B buffer for $10 \mathrm{~min}$. The samples were rinsed with distilled water several times and were air-dried again at room temperature. Stained blood smears were examined under a light microscope with oil-immersion at 1,000× magnification (BM2000, Jiangnan Yongxin Co., Ltd. Nanjing, China).

\section{Cytochemical staining}

Cytochemical staining was carried out according to the methods described by Xu (2003), with minor modifications. The prepared blood smears were fixed with formaldehyde vapor for Sudan black B (SBB) and acid phosphatase (ACP) staining, 10\% methanol-formaldehyde solution for alkaline phosphatase (ALP) and chloroacetic acid AS-D naphthol esterase (AS-D) 
120 staining, and 95\% ethanol solution for periodic acid-schiff's (PAS) and $\alpha$-naphthol esterase $(\alpha-$

121 NAE) staining. The specific staining procedures are briefly described as follows: (Sangon, 54827-17-7) dissolved in $100 \mathrm{ml} \mathrm{88 \%} \mathrm{ethanol} \mathrm{solution)} \mathrm{was} \mathrm{mixed} \mathrm{with} 20 \mu 1$ sodium nitroferricyanide (Sangon, 13755-38-9) saturated solution and dropped on the smears. Then 0.7 ml dilute $\mathrm{H}_{2} \mathrm{O}_{2}$ solution $\left(50 \mu 11 \% \mathrm{H}_{2} \mathrm{O}_{2}\right.$ solution mixed with $10 \mathrm{ml}$ distilled water) was added after the smears had been standing for $1 \mathrm{~min}$, and was air blown until distributed evenly and oxidized for $6 \mathrm{~min}$. staining solution for $60 \mathrm{~min}$ at $37^{\circ} \mathrm{C}$, then rinsed in $70 \%$ ethanol solution and distilled water for 1-2 min.

PAS staining: blood smears were oxidized with $10 \mathrm{mg} / \mathrm{ml}$ periodic acid for $18-20 \mathrm{~min}$, and rinsed in distilled water for 2 min. Samples were placed in Schiff's solution for $60-90$ min at $37^{\circ} \mathrm{C}$. After rinsing in a sulfuric acid solution (0.6 g sodium bisulfite (Sangon, 7681-57-4) dissolved in $5 \mathrm{ml} \mathrm{1mol} / 1$ hydrochloric acid and $100 \mathrm{ml}$ distilled water) three to four times, the smears were washed with distilled water for 2-3 min. 
139

140

141

142

143

144

washed with distilled water for $5 \mathrm{~min}$ and were immersed in $2 \%$ ammonium sulfide solution (Aladdin, 12135-76-1) for $30 \mathrm{~min}$.

\section{AS-BI phosphate (Sangon, 1919-91-1), dissolved in $10 \mathrm{ml} 0.05 \mathrm{~mol} / 1$ propanediol buffer, mixed} with $10 \mathrm{mg}$ fast blue B salt (Yuanye, 14263-94-6), and then filtered) for 45-60 $\mathrm{min}$ at $37^{\circ} \mathrm{C}$, and rinsing in distilled water for $2 \mathrm{~min}$.

AS-D staining: blood smears were stained with the incubation solution (10 $\mathrm{mg}$ chloroacetic acid AS-D naphthol (Sangon, 528-66-5), dissolved in $0.5 \mathrm{ml}$ acetone solution, and then mixed in $5 \mathrm{ml}$ distilled water, $5 \mathrm{ml} \mathrm{pH} 7.5$ Veronal acetic acid buffer, and $10 \mathrm{mg}$ fast blue B salt (Yuanye, 14263-94-6) were added). Samples were then incubated for $60-80 \mathrm{~min}$ at $37^{\circ} \mathrm{C}$, and washed with distilled water.

$\alpha$-NAE staining: the smears were placed in the reaction solution (100 $\mathrm{ml}$ phosphate buffer mixed with $1 \mathrm{ml} 4 \mathrm{mg} / \mathrm{ml} \alpha$-naphthol acetate (Sangon, 90-15-3), then $100 \mathrm{mg}$ fast blue B salt was added (Yuanye, 14263-94-6), and filtered by oscillation) and samples were incubated for 45-60 min at $37^{\circ} \mathrm{C}$ and washed with distilled water three to four times.

After cytochemical staining, the smears were counterstained with Wright's reagent for POX and SBB, $20 \mathrm{mg} / \mathrm{ml}$ methyl green (Sangon, 7114-03-6) for PAS, ACP, and $\alpha-\mathrm{NAE}$, and $1 \mathrm{mg} / \mathrm{ml}$ hematoxylin (Sangon, 517-28-2) for ALP and AS-D.

\section{Evaluation of cytochemical staining results}


The results of cytochemical staining were expressed in terms of the intensity of

159

160

161

162

163

164

165

166

167

168

169

170

171

172

173

174

175

$176 \mathrm{MCH}(\mathrm{pg})=\mathrm{Hb} / \mathrm{RBC}$

cytochemical reactions (negative reaction $(-)$, weak positive reaction $(+)$, positive reaction $(++)$

and strong positive reaction $(+++)$ ), according to the evaluation method described by Bianchi et

\section{Blood cell counts and measurements}

The total number of blood cells was calculated using a hemocytometer under an Olympus BX61 microscope (Tokyo, Japan). The number of erythrocytes (RBC), leukocytes (WBC), and thrombocytes (TC) were calculated according to the proportions of these cells counted on the Wright's blood smears (total number $\times$ the percentage of cells). The percentages of different leukocyte types were calculated after counting 3,000 randomly-selected leukocytes from males and females. The cell sizes (the length and width of various cells and nuclei) were obtained using an ocular micrometer scale by measuring 20 randomly-selected cells for each cell type from male and female specimens. The hemoglobin $(\mathrm{Hb})$, hematoceit $(\mathrm{HCT})$, and erythrocyte sedimentation rate (ESR) were determined according to the methods described previously (Peng, et al., 2018). The mean corpuscular volume (MCV), mean corpuscular hemoglobin (MCH), and mean corpuscular hemoglobin concentrations (MCHC) were calculated from RBC, HCT, and $\mathrm{Hb}$ according to the formulae below (Gao et al., 2007a):

$\operatorname{MCV}(\mathrm{fl})=\mathrm{HCT} / \mathrm{RBC}$ 


\section{Statistical analysis}

The experimental data were represented by mean \pm SD. The significant differences in morphometric values among different cell types or between sexes were compared by one-way ANOVA analysis using SPSS 21.0 software (SPSS Inc, Chicago, USA). A P-value less than 0.05 was used to indicate a significant difference, and a P-value less than 0.01 indicated an extremely significant difference.

\section{Results}

\section{Classification and counting of peripheral blood cells} nuclei, nucleo-cytoplasmic ratio, the presence or absence of particles, and tinctorial feature in the cytoplasm, the peripheral blood cells of $O$. argus could be divided into erythrocytes, leukocytes, and thrombocytes, and the leukocytes could be further subdivided into neutrophils, monocytes, large lymphocytes, and small lymphocytes. difference in the number of erythrocytes and total leukocytes between sexes $(\mathrm{P}>0.05)$, while the number of thrombocytes in females was significantly higher than that in males $(\mathrm{P}<0.05)$. The 
196

197

198

199

200

201

202

203

204

205

206

207

208

209

210

211

212

213

number of different leukocytes were also shown in Table 1. Monocytes were the most abundant

leukocytes in $O$. argus, followed by neutrophils and small lymphocytes, and large lymphocytes

were the least numerous (one-way ANOVA: $F_{4,11}=354.476 . P<0.01$ ). The number of large

lymphocytes and small lymphocytes in females was significantly lower than that in males (P

$<0.05)$. No statistically significant differences in $\mathrm{Hb}, \mathrm{HCT}, \mathrm{ESR}, \mathrm{MCV}, \mathrm{MCH}$, and MCHC were

found between females and males $(\mathrm{P}>0.05)$.

\section{The microstructure of peripheral blood cells}

\section{Erythrocytes}

Mature erythrocytes (Fig. 1A) were oval in shape, with a smooth surface, and contained an ovoid or rod-shaped purple nucleus in the center of the cell, with a light brown or yellowish cytoplasm. The size of the mature erythrocytes and their nuclei are shown in Table 2 . The cell

length, and nuclear length and width of mature erythrocytes in females were significantly larger than those in males $(\mathrm{P}<0.01)$. A small number of immature erythrocytes (Fig. 1A) were also observed on the blood smears treated with Wright's staining, and were round and smaller than mature erythrocytes, with round or elliptic, dark purplish-stained nuclei.

\section{Neutrophils}

Neutrophils (Fig. 1B, C) were spherical or round in shape, with purplish stained nuclei. The nuclei had a variety of shapes, including bilobate, trilobed, kidney-shaped (or non-bilobed), and 
214 bilobed, which were the most frequently observed. The cytoplasm was rich and stained light blue,

215 containing numerous fine mauve and reddish particles.

\section{Monocytes}

217 Monocytes (Fig. 1D) were the largest leukocytes in O. argus (Table 2). Most of them were

218 round and oval and a few were irregular. The nuclei were oval, pear-shaped, or horseshoe-shaped,

219 and generally stained purple. The most obvious morphological feature of monocytes was that the

220 cytoplasm contained a large number of vacuoles of different sizes with pseudopodia

221 protuberances at the cell edges.

\section{Large lymphocytes}

Lymphocytes could be classified as large and small lymphocytes. Large lymphocytes (Fig.

1E) were generally or irregularly round, with large, oval nuclei on one side of the cells; the surfaces and some had small finger-like protuberances on the surface of the cells.

\section{Small lymphocytes} nucleus that occupied almost the entire cell, and contained a thin rim of pale blue cytoplasm. cytoplasmic margins.

\section{Thrombocytes}



and spindle. Spindle-shaped thrombocytes (Fig. 1G) were usually isolated and their nuclei were consistent with the shape of the cells, most of which were centered and purplish, and the

cytoplasm was nearly colorless. Round thrombocytes (Fig. 1H) usually appeared in clusters with

237 multiple cells, with round, dark purple-stained nuclei, and less cytoplasm was flocculent around 238 the nucleus.

\section{The cytochemical staining characteristics of peripheral blood cells}

\section{POX staining}

Neutrophils (Fig. 2AB) were strongly positive with blue-black, coarse, and rod-shaped

granules in the cytoplasm. The cytoplasms of erythrocytes (Fig. 2AA), monocytes (Fig. 2AC),

large lymphocytes (Fig. 2AD), small lymphocytes (Fig. 2AE), and thrombocytes (Fig. 2AF)

were light blue without granules; all of these cells were negative.

\section{SBB staining} and thrombocytes (Fig. 2BG) were pale purple without granules; all of these cells were negative.

\section{PAS staining}


252 lymphocytes, and thrombocytes (Fig. 2CC-CH) were purple or dark purple with diffusely

253 granular matter; all of these cells were positive.

\section{ACP staining}

Neutrophils (Fig. 2DE) contained a large number of brown-black granules or tablets in the cytoplasm and were strongly positive. Monocytes (Fig. 2DF) and thrombocytes (Fig. 2DI) were weakly positive, with a small number of brown granules in the cytoplasm. The cytoplasms of erythrocytes (Fig. 2DD), large lymphocytes (Fig. 2DG), and small lymphocytes (Fig. 2DH) were pale purple without granules; all of these cells were negative.

260

261

262

263

264

265

266

267

268

269

\section{ALP staining}

Both neutrophils (Fig. 2EF) and large lymphocytes (Fig. 2EH) were weakly positive, with many fine, uniformly-distributed purple granules in the cytoplasm. The cytoplasms of erythrocytes (Fig. 2EE), monocytes (Fig. 2EG), small lymphocytes (Fig. 2EI), and thrombocytes (Fig. 2EJ) were pale yellow without stained granules; all of these cells were negative.

\section{AS-D staining}

Neutrophils (Fig. 2FG) were positive, uniformly-distributed red granules. The cytoplasms of monocytes (Fig. 2FH), large lymphocytes (Fig. 2FI), small lymphocytes (Fig. 2FJ), and thrombocytes (Fig. 2FK) were pale red with fine granules; all of these cells were weakly positive. Erythrocytes (Fig. 2FF) were negative with a pale pink cytoplasm. 
270

271

272

273

274

275

276

277

278

279

280

281

282

283

284

285

286

287

288

\section{a-NAE staining}

The cytoplasm of monocytes (Fig. 2GI) was filled with gray-black diffused or granular deposits, which were positive. The cytoplasms of neutrophils (Fig. 2GH), large lymphocytes (Fig. 2GJ), and small lymphocytes (Fig. 2GK) were purple with dark brown or purple granules; all of these cells were weakly positive. Erythrocytes (Fig. 2GG) and thrombocytes (Fig. 2GL) were negative; their cytoplasm were purplish without granules.

\section{The cytochemical staining patterns of peripheral blood cells}

The cytochemical staining patterns of peripheral blood cells in $O$. argus are summarized in Table 3. Erythrocytes were positive for PAS and negative for POX, SBB, ACP, ALP, AS-D, and $\alpha-N A E$ staining. Neutrophils exhibited a strongly positive reaction for POX, SBB, and ACP; positive for PAS, and AS-D; and weakly positive for ALP and $\alpha$-NAE staining. Monocytes were positive for PAS and $\alpha-\mathrm{NAE}$; weakly positive for ACP and AS-D; and negative for POX, SBB, and ALP staining. Large lymphocytes were positive for PAS and weakly positive for ALP, AS-D, and $\alpha$-NAE, while negative for POX, SBB and ACP staining. Small lymphocytes were positive for PAS, and weakly positive for AS-D and $\alpha-\mathrm{NAE}$, while negative for POX, SBB, ACP, and ALP staining. Thrombocytes showed a positive reaction for PAS and a weakly positive reaction for ACP and AS-D, but were negative for all the other cytochemical staining. 
309

310

311

312

313

314

315

316

317

318

319

320

321

322

323

324

325

326

327 328 shape, with a larger, elliptic nucleus. Guerrero, 2007).

more oxygen and had correspondingly higher values of RBC, Hb, and HCT (Engel \& Davis, 1964; Molnár \& Tamássy, 1970; Rambhaskar \& Rao, 1987). This study showed that there was no significant difference in the values of $\mathrm{RBC}, \mathrm{Hb}$, and HCT between males and females, which was consistent with most fish, such as the Persian sturgeon (Milad et al., 2016), Siamese fighting fish (Motlagh et al., 2012), shovelnose catfish (Negrete et al., 2010), and cichlid fish (Vázquez \&

The morphological characteristics of mature erythrocytes of $O$. argus were similar to those of other fish (Ahmed \& Sheikh., 2020; Chen et al., 2019a; Negrete et al., 2010; Vázquez \& Guerrero, 2007), which were usually oval in shape with an oval or long-oval nucleus. The size of erythrocytes in O. argus was smaller than in the Chinese sturgeon (Acipenser sinensis) and sisorid catfish (Glyptosternum maculatum), larger than in the Siamese fighting fish and cichlid fish, and similar to the piebald naked carp (Table 4). The erythrocyte size reflects the oxygen transport capacity, and small erythrocytes are better able to transport oxygen (Fang et al., 2014).

We found a small number of immature erythrocytes in the peripheral blood of $O$. argus, which was consistent with reports in other fish. However, the morphology of immature erythrocytes in $O$. argus were round with a smaller and mostly-round nucleus, which was somewhat different from that of other fish, such as S. prenanti (Fang et al., 2014), the spotted rose snapper (Rio-Zaragoza et al., 2011), piebald naked carp (Tang et al., 2015), crucian carp, and grass carp (Zhang et al., 2019), whose immature erythrocytes were mostly ovoid or oval in 

granulocytes in vertebrates: neutrophils, eosinophils, and basophils (Fang et al., 2014). Almost certain species (Zhou et al., 2006). Few fish other than tilapia (Oreochromis niloticus) (Ueda et eosinophils (Shigdar, Harford \& Ward, 2009; Zhang et al., 2019), and some fish have neither eosinophils nor basophils (Chen et al., 2019a; Fang et al., 2014; Tavares-dias \& Moraes, 2006;

Da Silva et al., 2011; Zhang et al., 2011). We did not find eosinophils and basophils in the peripheral blood of $O$. argus. were the most abundant leukocytes in most of the fish, such as the South American catfish (Bianchi et al., 2014), turbot (Psetta maxima) (Burrows, Fletcher \& Manning, 2001), Siamese fighting fish (Motlagh et al., 2012), shovelnose catfish (Negrete et al., 2010), spotted rose snapper (Rio-Zaragoza et al., 2011), piebald naked carp (Tang et al., 2015), cichlid fish (Vázquez

347 \& Guerrero, 2007), and sisorid catfish (Zhang et al., 2011). Neutrophils were most common in some fish, such as the Persian sturgeon (Milad et al., 2016) and S. prenanti (Fang et al., 2014). 
349 Monocytes were found to be the most abundant leukocytes in $O$. argus, similar to the Chinese

350 sturgeon (Gao et al., 2007b).

351 Fish monocytes are mostly round and oval (though a few are irregular in shape), have

352 phagocytic functions, and are extremely sensitive to environmental variations (Zheng et al.,

353 2016). Mononcytes were the largest leukocytes in O. argus, and were significantly larger than

354 those of S. prenanti (Fang et al., 2014), the spotted rose snapper (Rio-Zaragoza et al., 2011),

355 piebald naked carp (Tang et al., 2015), and neotropical fish (Tavares-Dias \& Moraes, 2006). The

356 most distinct morphological characteristic of monocytes in $O$. argus was that their cytoplasm

357 contained vacuoles of different sizes and pseudopodia protuberances on the cell edge, which was

358 consistent with the monocytes reported in other fish (Tavares-Dias, 2006; Tripathi, Latimer \&

359 Burnley, 2004; Zheng et al., 2016) and may be related to their phagocytic function (Zheng et al., 360 2016).

361 Lymphocytes belong to agranulocytes and play an important role in both innate and

362 acquired immunity (Shigdar, Harford \& Ward, 2009). Compared with the lymphocytes in some

363 other fish (Tavares-dias, 2006; Zheng et al., 2016), the lymphocytes in O. argus were variable in

364 size and were classified as large lymphocytes and small lymphocytes. Most of the large

365 lymphocytes had small finger-like protuberances on the cell surface. Many microvilli

366 protuberances can also be found in the cytoplasmic edges of small lymphocytes. These features

367 have also been reported in other fish (Burrows, Fletcher \& Manning, 2001; Rio-Zaragoza et al.,

368 2011; Vázquez \& Guerrero, 2007; Da Silva et al., 2011), and the protuberances on the surface of 
369 lymphocytes may be related to the immune function of antigen binding receptor molecules

370 (Scapigliati, 2013).

371

372

373

374

375

376

377

Neutrophils in $O$. argus were usually round or spherical with a bilobate nucleus, their cytoplasm contained numerous fine mauve and reddish granules; these morphological characteristics were somewhat different from the reports in some other fish. For instance, the neutrophils of S. prenanti (Fang et al., 2014) were round or irregular-shaped, their nuclei were usually kidney-shaped or trilobed, and their cytoplasm contained a large number of light blue or pink granules. The neutrophils of the shovel-nose catfish (Negrete et al., 2010) had eccentric and round nuclei with light blue granules in the cytoplasm; neutrophils of neotropical fish (TavaresDias \& Moraes., 2006) were round with an oval-shaped, eccentric nucleus; their cytoplasm contained many purple granules of different sizes. The heterophils of the sisorid catfish (Zhang et al., 2011) were round and regular in shape with kidney-shaped or round nuclei, and the cytoplasm contained pale blue granules.

\section{The morphology and number of thrombocytes in $O$. argus}

Different thrombocyte shapes, including round, oval, oblong, and spindle-shaped, were observed in O. argus, which was consistent with the reports in other fish (Fang et al., 2014; Gao et al., 2007b; Micha et al., 2019; Rio-zaragoza et al., 2011; Zhang et al., 2011; Zheng et al., 2016). The spindle-shaped thrombocytes often existed alone with some vacuoles in the cytoplasm and were related to cell phagocytosis (Nagasawa, Somamoto \& Nakao, 2015; Stosik 
388

389

390

391

392

393

394

395

396

397

et al., 2002). The round thrombocytes usually appeared in clusters with two to eight cells, which may be related to their hemostatic function (Chen et al., 2019b; Peng et al., 2018).

The number of thrombocytes in $O$. argus was lower than that of the Siamese fighting fish

(Motlagh et al., 2012), shovel-nose catfish (Negrete et al., 2010), and spotted rose snapper (RioZaragoza et al., 2011); higher than that of the Chinese sturgeon (Gao et al., 2007b) and piebald naked carp (Tang et al., 2015); and similar to grass carp, blunt snout bream (Megalobrama amblycephala), yellow catfish (Pelteobagrus fulvidraco) (Chen et al., 2019), and cichlid fish (Vázquez \& Guerrero, 2007). The differences in the number of thrombocytes in different species of fish may be related to biotic and abiotic factors and their adaptability to the environment (Pavlidis et al., 2007; Prasad \& Charles, 2010).

\section{The cytochemical staining patterns of blood cells in $O$. argus}

We studied the cytochemical characteristics of peripheral blood cells of $O$. argus using seven staining methods, including POX, SBB, PAS, ACP, ALP, AS-D, and $\alpha$-NAE for the first time. POX is enzyme-specific to neutrophils in mammals and participates in the defense mechanism of bacterial infection (Tavares-Dias, 2006). SBB and PAS staining were used to detect intracellular glycogen and lipids, which may provide energy for phagocytosis (Ueda et al., 2001). ACP and ALP are lysosomal enzymes involved in phagocytosis and degradation (Shigdar,

Harford \& Ward, 2009; Da Silva et al, 2011). AS-D is a specific esterase, which is associated with cellular defense and phagocytic material processing (Casaletti-Rosa \& Lunardi, 1997; 
407 Tavares-Dias et al., 2007). As a non-specific esterase, $\alpha$-NAE plays an important role in

408 phagocytosis and antigen presentation (Fang et al., 2014).

409

The erythrocytes observed in this study were only positive for PAS, which was different from results in other fish, such as $S$. prenanti (Fang et al., 2014), tilapia (Ueda et al., 2001), crucian carp, grass carp (Zhang et al., 2019), and piebald naked carp (Zheng et al., 2016), whose erythrocytes were negative for PAS. The erythrocytes in $O$. argus were negative for POX, SBB, ACP, ALP, AS-D, and $\alpha$-NAE staining, which was consistent with the fish listed above. PAS positivity and SBB negativity indicated that glycogen is the main energy source of erythrocytes in $O$. argus. and were positive for PAS and AS-D, and weakly positive for ALP and $\alpha$-NAE staining. These results were generally similar to the staining results of the Murray cod (Maccullochella peelii peelii) (Shigdar, Harford \& Ward, 2009), but different from reports in other fish. For instance, neutrophils of the fat snook (Centropomus parallelus) (Da Silva et al., 2011) were positive for PAS, SBB, ACP, and NAE, but negative for ALP staining. The American paddlefish (Polyodon 422 spathula) (Petrie-Hanson \& Peterman, 2005) and piebald naked carp (Gymnocypris eckloni)

423 (Zheng et al., 2016) were positive for ACP, but negative for SBB staining. The Asian sun catfish 424 (Horabagrus brachysoma) (Prasad \& Charles., 2010) was negative for ALP, NAE, and ASD 425 staining. Neutrophils in human and mammals are mainly involved in the phagocytosis and 426 degradation of invading microorganisms (Azevedo and Lunardi, 2003; Rieger and Barreda, 2011; 
427 Wang et al., 2019). The strongly positive reactions for POX, SBB, and ACP and the positive

428 reactions for PAS, ACP, AS-D, and $\alpha-\mathrm{NAE}$ indicated that the neutrophils of $O$. argus are similar

429 to those of mammals, which have strong phagocytic and bactericidal abilities. South American catfish (Bianchi et al., 2014), four freshwater teleosts (Tavares-Dias, 2006), channel catfish (Ictalurus punctactus) (Tavares-Dias \& Moraes, 2007), and fat snook (Da Silva et al., 2011), whose lymphocyte were negative for PAS. However, the results were consistent with S. prenanti (Fang et al., 2014), tilapia (Ueda et al., 2001) and piebald naked carp (Zheng et al., 2016), suggesting that there were certain glycogen in the lymphocytes of $O$. argus. negative for all other cytochemical staining. These results were similar to those of the Murray cod (Shigdar, Harford \& Ward, 2009), tilapia (Ueda et al., 2001), and piebald naked carp (Zheng 
447 et al., 2016). The thrombocytes of lower vertebrates are functionally similar to platelets in

448 mammals (Micha et al., 2019), playing an important role in the process of hemostasis and

449 coagulation (Chen et al., 2018; Peng et al., 2018). Studies have investigated whether

450 thrombocytes in some fish have phagocytotic abilities (Michał et al., 2019; Shigdar et al., 2007;

451 Shigdar, Harford \& Ward, 2009; Da Silva et al, 2011; Zhang et al., 2019). In this study, the

452 thrombocytes of $O$. argus were positive for PAS, ACP, and AS-D staining, indicating that they

453 may have some phagocytic and material-processing functions.

We conducted a comprehensive study on the morphological metrology, microstructure, and cytochemical characteristics of peripheral blood cells in $O$. argus for the first time. The results showed that the number of erythrocytes and leukocytes in $O$. argus was consistent with that of similar to those of other fish, while the cytochemical staining patterns have clear species specificity. For example, all of the blood cell types of $O$. argus were positive for PAS; neutrophils were strongly positive or positive for all the seven kinds of cytochemical staining; monocytes, large lymphocytes, and small lymphocytes were negative for POX and SBB; and morphology and function of peripheral blood cells of fish, and provide basic data for health assessments in $O$. argus aquaculture. 
467 Ahmed I, Sheikh AZ. 2020. Comparative study of hematological parameters of snow trout 468 Schizopyge plagiostomus and Schizopyge niger inhabiting two different habitats. The European Zoological Journal 87(1):12-19.

470

471

472

473

474

475

476

477

478

479

480

481

482

483

484

485

Azevedo A, Lunardi LO. 2003. Cytochemical characterization of eosinophilic leukocytes circulating in the blood of the turtle (Chrysemys dorbignih). Acta Histochemica 105(1):99105.

Bianchi MB, Jerônimo GT, Pádua SB, Satake F, Ishikawa MM, Tavares-Dias M, Martins ML. 2014. The hematological profile of farmed Sorubim lima: reference intervals, cell morphology and cytochemistry. Veterinarski Arhiv 84(6):677-690.

Burrows AS, Fletcher TC, Manning MJ. 2001. Haematology of the turbot, Psetta maxima (L.): ultrastructural, cytochemical and morphological properties of peripheral blood leucocytes. Journal of Applied Ichthyology 17(2):77-84.

Casaletti-Rosa L, Lunardi LO. 1997. Comparative study of the localization of nonspecific esterase activity (Naphthyl butyrate) in leukocytes from reptiles, birds and fish. Brazilian Journal of Morphology Science 14,72.

Chen HJ, Yuan GL, Su JG, Liu XL. 2019a. Hematological analysis of Ctenopharyngodon idella, Megalobrama amblycephala and Pelteobagrus fulvidraco: Morphology, ultrastructure, cytochemistry and quantification of peripheral blood cells. Fish \& Shellfish Immunology 90:376-384. 
486 Chen XX, Wang J, Wei QQ, Misbah H, Li E, Zhang SZ. 2019b. Morphology and

487

488

489

490

491

492

493

494

495

496

497

498

499

500

501

502 cytochemical patterns of peripheral blood cells in domestic pigeon (Columba livia). Tissue and Cell 59:10-17.

Chen XX, Wei QQ, Wang J, Peng F, Li E, Zhou YK, Zhang SZ. 2018. Cytochemical patterns of the peripheral blood cells in Chinese alligator (Alligator sinensis). Tissue and Cell 55:7176.

Courtenay JrWR, Williams JD. 2004. Snakeheads (Pisces, Channidae)-A Biological Synopsis and Risk Assessment. U.S. Geological Survey Circular 1251:1-143.

Da Silva WF, Egami MI, Santos AA, Antoniazzi MM, Silva M, Gutierre RC, Paiva MJR. 2011. Cytochemical, immunocytochemical and ultrastructural observations on leukocytes and thrombocytes of fat snook (Centropomus parallelus). Fish and Shellfish Immunology 31(4):571-577.

Engel DM, Davis EM. 1964. Relationship Between Activity and Blood Composition in Certain Marine Teleosts. Copeia 3(4):586-587.

Fang J, Chen K, Cui HM, Peng X, Li T, Zuo ZC. 2014. Morphological and Cytochemical Studies of Peripheral Blood Cells of Schizothorax prenanti. Anatomia Histologia Embryologia 43(5):386-394. 
503 Fazio F, Faggio C, Marafioti S, Torre A, Piccione G. 2012. Comparative study of

504

505

506

507

508

509

510

511

512

513

514

515

516

517

518

519

520

521

haematological profile on Gobius niger in two different habitat sites: Faro Lake and Tyrrhenian Sea. Cahiers De Biologie Marine 53(2):213-219.

Ferdous F, Scott TR. 2015. A comparative examination of thrombocyte/platelet immunity. Immunology Letters 163(1):32-39.

Gao ZX, Wang WM, Khalid A, Zhou XY, Yang Y, James SD, Wang HP, Wang HL, Yang L, Sun YH. 2007a. Haematological characterization of loach Misgurnus anguillicaudatus: Comparison among diploid, triploid and tetraploid specimens. Comparative Biochemistry and Physiology - Part A Molecular \& Integrative Physiology 147(4):1001-1008.

Gao ZX, Wang WM, Yang Y, Khalid A, Li DP, Zou GW, James SD. 2007b. Morphological Studies of Peripheral Blood Cells of the Chinese sturgeon, Acipenser sinensis. Fish Physiology and Biochemistry 33(3):213-222.

Grant KR. 2015. Fish Hematology and Associated Disorders, Veterinary Clinics of North America Exotic Animal Practice 18(1):83-103.

Ishikawa NM, Ranzani-Paiva MJT, Lombardi JV. 2008. Total leukocyte counts methods in fish, Oreochromis niloticus. Archives of Veterinary Science 13(1):54-63.

Jawad LA, Al-Mukhtar MA, Ahmed HK. 2004. The relationship between haematocrit and some biological parameters of the Indian shad, Tenualosa ilisha (Family Clupeidae). Animal Biodiversity and Conservation 27(2):47-52.

Peer) reviewing PDF | (2020:07:51298:6:0:NEW 16 Mar 2021) 
522 Kori-Siakpere O, Ake JEG, Idoge E. 2005. Haematological characteristics of the African 523 snakehead, Parachanna obscura. African Journal of Biotechnology 4(6):527-530.

524

525

526

527

528

529

530

531

532

533

534

535

536

537

538

539

540

Martins ML, Xu DH, Shoemaker CA, Klesius PH. 2011. Temperature effects on immune response and hematological parameters of channel catfish Ictalurus punctatus vaccinated with live theronts of Ichthyophthirius multifiliis. Fish and shellfish immunology 31(6):774780.

Massar B, Dey S, Barua R, Dutta K. 2012. Microscopy and Microanalysis of Hematological Parameters in Common Carp, Cyprinus carpio, Inhabiting a Polluted Lake in North East India. Micros, Microscopy \& Microanalysis 18(5):1077-1087.

Michał S, Beata T, Wiesław D. 2019. Characterisation of Thrombocytes in Osteichthyes. Journal of veterinary research 63:123-131.

Milad A, Kumar PS, Shafigh S, Hasan F, Jalil ZM. 2016. Comparative study of haematological, serum electrolyte and nonelectrolyte parameters of male and female Persian sturgeon (Acipenser persicus) brood stocks. Acta Oceanologica Sinica 35(8):39-43.

Minasyan HA. 2014. Erythrocyte and Leukocyte: Two Partners in Bacteria Killing. International Reviews of Immunology 33:490-497.

Molnár G, Tamássy E. 1970. Study of the haemoglobin content of a single erythrocyte (M index) in various cultured fish species. Journal of Fish Biology 2:171-267.

Motlagh SP, Zarejabad AM, Nasrabadi RG, Ahmadifar E, Molaee M. 2012. Haematology, 
541

542

543

544

545

546

547

morphology and blood cells characteristics of male and female Siamese fighting fish (Betta splendens). Comparative Clinical Pathology 21(1):15-21.

Nagasawa T, Somamoto T, Nakao M. 2015. Carp thrombocyte phagocytosis requires activation factors secreted from other leukocytes. Developmental and Comparative Immunology 52:107-111.

Negrete JCC, Correa AAG, Guevara MJP, García VJA, Carrasco SCP. 2010. Characterization of blood cells and hematological parameters in trans-andean shovelnose catfish Sorubim cuspicaudus. Zootecnia Tropical 27(4):393-405.

\section{Palmer L, Briggs C, Mcfadden S, Zini G, Burthem J, Rozenberg G, Proytcheva M, Machin}

SJ. 2015. ICSH recommendations for the standardization of nomenclature and grading of peripheral blood cell morphological features. International Journal of Laboratory Hematology 37(3):287-303.

Pavlidis M, Futter WC, Katharios P, Divanach P. 2007. Blood cell profile of six Mediterranean mariculture fish species. Journal of Applied Ichthyology 23(1):70-73.

Peng F, Chen XX, Meng T, Li E, Zhou YK, Zhang SZ. 2018. Hematology and serum biochemistry parameters of captive Chinese alligators (Alligator sinensis) during the active and hibernating periods. Tissue and Cell 51: 8-13. 
558 Petrie-Hanson L, Peterman AE. 2005. American paddlefish leukocytes demonstrate 559 mammalian-like cytochemical staining characteristics in lymphoid tissues. Journal of Fish Biology 66(4):1101-1115.

561

562

563

564

565

566

567

568

569

570

571

572

573

574

575

576

Prasad G, Charles S. 2010. Haematology and leucocyte enzyme cytochemistry of a threatened yellow catfish Horabagrus brachysoma (Gunther 1864). Fish Physiology and Biochemistry 36(3):435-443.

Rambhaskar B, Rao SK. 1987. Comparative haematology of ten species of marine fish from Visakhapatnam Coast. Journal of Fish Biology 30(1):59-66.

Rieger AM, Barreda DR. 2011. Antimicrobial mechanisms of fish leukocytes. Developmental and Comparative Immunology 35(12):1238-1245.

Rio-Zaragoza OBD, Fajer-ávila EJ, Almazán-Rueda P, Abdo de la Parra MI. 2011. Hematological characteristics of the spotted rose snapper Lutjanus guttatus (Steindachner, 1869) healthy and naturally infected by dactylogyrid monogeneans. Tissue and Cell 43:137-142.

Sagada G, Chen JM, Shen BQ, Huang AX, Sun LH, Jiang JH, Jin CH. 2017. Optimizing protein and lipid levels in practical diet for juvenile northern snakehead fish(Channa argus). Animal Nutrition 3(2):156-163.

Satheeshkumar P, Ananthan G, Senthilkumar D, Khan AB, Jeevanantham K. 2012. Comparative investigation on haematological and biochemical studies on wild marine 
577

578

579

580

581

582

583

584

585

586

587

588

589

590

591

592

593

594

595

teleost fishes from Vellar estuary, southeast coast of India. Comparative Clinical Pathology 21(3):275-281.

Satheeshkumar P, Senthilkumar D, Ananthan G, Soundarapandian P, Khan AB. 2011. Measurement of hematological and biochemical studies on wild marine carnivorous fishes from Vellar estuary, southeast coast of India. Comparative Clinical Pathology 20(2):127134.

Scapigliati G. 2013. Functional aspects of fish lymphocytes. Developmental and Comparative Immunology 41(2):200-208.

Shigdar S, Cook D, Jones P, Harford A, Ward AC. 2007. Blood cells of Murray cod Maccullochella peelii peelii (Mitchell). Journal of Fish Biology 70(3):973-980.

Shigdar S, Harford A, Ward AC. 2009. Cytochemical characterisation of the leucocytes and thrombocytes from Murray cod (Maccullochella peelii peelii, Mitchell). Fish and Shellfish Immunology 26(5):731-736.

Stosik M, Deptula W, Trávniček M, Baldy-Chudzik K. 2002. Phagocytic and bacterial activity of blood thrombocytes in carps (Cyprinus carpio). Veterinarni Medicina, 47(1):2125.

Tang Y, Peng X, Fang J, Cui HM, Zuo ZC, Deng JL. 2015. Characterization of hematological parameters and blood cells of cultured Gymnocypris eckloni Herzenstein, 1891. Journal of Applied Ichthyology 31(5):931-936. 
596 Tavares-Dias M. 2006. A morphological and cytochemical study of erythrocytes, thrombocytes

597

598

599

600

601

602

603

604

605

606

607

608

609

610

611

612

613

614 and leukocytes in four freshwater teleosts. Journal of Fish Biology 68(6):1822-1833.

Tavares-Dias M, Moraes F. 2004. Hematologia de peixes teleósteos. Ribeirão Preto, São Paulo: Villimpress $144 \mathrm{p}$.

Tavares-Dias M, Moraes F. 2006. Morphological, cytochemical, and ultrastructural study of thrombocytes and leukocytes in neotropical fish, Brycon orbignyanus Valenciennes, 1850 (Characidae, Bryconinae). Journal of Submicroscopic Cytology and Pathology 38(23):209-215.

Tavares-Dias M, Moraes F. 2007. Leukocyte and thrombocyte reference values for channel catfish (Ictalurus punctatus Raf), with an assessment of morphologic, cytochemical, and ultrastructural features. Veterinary Clinical Pathology 36(1):49-54.

Tavares-Dias M, Ono EA, Pilarski F, Moraes F. 2007. Can thrombocytes participate in the removal of cellular debris in the blood circulation of teleost fish? A cytochemical study and ultrastructural analysis. Journal of Applied Ichthyology 23(6):709-712.

Tripathi NK, Latimer KS, Burnley VV. 2004. Hematologic reference intervals for koi (Cyprinus carpio), including blood cell morphology, cytochemistry, and ultrastructure. Veterinary Clinical Pathology 33(2):74-83.

Vázquez GR, Guerrero GA, 2007. Characterization of blood cells and hematological parameters in Cichlasoma dimerus (Teleostei, Perciformes). Tissue and Cell 39:151-160. 
615 Ueda IK, Egami MI, Sasso WDS, Matushima ER. 2001. Cytochemical aspects of the 616 peripheral blood cells of Oreochromis (Tilapia) niloticus. (Linnaeus, 1758) (Cichlidae, 617 Teleostei): part II. Brazilian Journal of Veterinary Research and Animal Science 38(6): 273-277.

619

620

621

Wang Z, Lin LY, Chen WJ, Zheng X, Zhang YX, Liu Q, Yang DH. 2019. Neutrophil plays critical role during Edwardsiella piscicida immersion infection in zebrafish larvae. Fish and Shellfish Immunology 87:565-572.

Xiao MS, Hu QS, Zhao Y, Bao FY, Cui F, Zheng RQ. 2017. Development of 36 SNP markers in Ophiocephalus argus Cantor based on high-throughput sequencing. Conservation Genetics Resources 10(11):35-38.

Xu J , Bian C, Chen KC, Liu GM, Jiang YL, Luo Q, You XX, Peng WZ, Li J, Huang Y, Yi YH, Dong CJ, Deng H, Zhang SH, Zhang HY, Shi Q, Xu P. 2017. Draft genome of the Northern snakehead, Channa argus. Gigaence, 6(4):1-5.

Xu WR. 2003. Clinical Hematology and blood testing experimental guidance. Beijing: People's Medical Publishing House (in Chinese).

Zhang F M, Feng RR, Fang W, Shi YH, An LG, Yang GW. 2019. Cytochemical characterization of peripheral blood cell populations of two Cyprinidae, Carassius auratus and Ctenopharyngodon idellus. Anatomia Histologia Embryologia 48:22-32. 
633 Zhang HJ, Xie CX, Li DP, Liu HP, Yang XF. 2011. Blood cells of a sisorid catfish 634 Glyptosternum maculatum (Siluriformes: Sisoridae), in Tibetan Plateau. Fish Physiology 635 and Biochemistry 37(1):169-176.

636

637

638

639

640

Zheng ZX, Tang Y, Fang J, Peng X, Fan JD, Cui HM, Yang LZ. 2016. Ultrastructural and cytochemical properties of peripheral blood cells of piebald naked carp (Gymnocypris eckloni). Anatomia Histologia Embryologia 46(1):17-24.

Zhou Y, Pan FG, Li YS, Yan GM. 2006. Morphological study on peripheral blood cells of kalugaa, Huso dauricus. Journal of Fishery Sciences of China 13:480-484 (in Chinese). 


\section{Table $\mathbf{1}$ (on next page)}

Haematological parameters of female and male argus snakehead.

Each data point represents the mean of three replicates $\pm S D$ and the range. *indicates significant differences in blood cell counts and haematological parameters between males and females $(P<0.05)$; different letters $(a, b, c, d)$ in the same column indicate significant differences between leukoyte types $(P<0.05)$. Coefficient of Variation (CV) $(\%)=($ Standard Deviation / Mean) $\times 100 \%$. TBC: total blood cell counts. 
1 Table 1: Haematological parameters of female and male argus snakehead.

\begin{tabular}{|c|c|c|c|c|}
\hline \multirow[b]{2}{*}{ parameters } & \multicolumn{2}{|l|}{ Female $(\mathrm{N}=15)$} & \multicolumn{2}{|l|}{ Male $(\mathrm{N}=15)$} \\
\hline & Mean $\pm \mathrm{SD}$ & Range & Mean \pm SD & Range \\
\hline $\mathrm{TBC}\left(\times 10^{6} / \mathrm{mm}^{3}\right)$ & $3.09 \pm 0.21$ & $2.90-3.30$ & $3.15 \pm 0.24$ & $2.85-3.45$ \\
\hline CV of TBC (\%) & 6.95 & & 7.70 & \\
\hline $\mathrm{RBC}\left(\times 10^{6} / \mathrm{mm}^{3}\right)$ & $2.96 \pm 0.16$ & $2.78-3.16$ & $3.01 \pm 0.24$ & $2.72-3.30$ \\
\hline CV of RBC (\%) & 5.41 & & 7.97 & \\
\hline $\mathrm{Hb}(\mathrm{g} / \mathrm{dl})$ & $10.53 \pm 0.37$ & $10.17-11.03$ & $10.60 \pm 0.29$ & $10.30-11.0$ \\
\hline $\mathrm{HCT}(\%)$ & $42.41 \pm 2.38$ & $39.45-45.27$ & $43.21 \pm 1.77$ & $41.52-45.66$ \\
\hline $\operatorname{ESR}(\mathrm{mm} / \mathrm{h})$ & $1.52 \pm 0.22$ & $1.23-1.76$ & $1.49 \pm 0.10$ & $1.42-1.63$ \\
\hline $\operatorname{MCV}(\mathrm{fl})$ & $143.51 \pm 13.54$ & $124.84-162.85$ & $144.86 \pm 14.15$ & $125.83-167.87$ \\
\hline $\mathrm{MCH}(\mathrm{pg})$ & $35.72 \pm 2.57$ & $32.17-39.69$ & $35.46 \pm 3.03$ & $31.21-40.44$ \\
\hline $\mathrm{MCHC}(\mathrm{g} / \mathrm{dl})$ & $24.56 \pm 2.59$ & $21.95-29.44$ & $24.73 \pm 2.03$ & $22.50-27.56$ \\
\hline $\mathrm{WBC}\left(\times 10^{4} / \mathrm{mm}^{3}\right)$ & $8.84 \pm 0.47$ & $8.29-9.44$ & $10.55 \pm 0.82$ & $9.55-11.56$ \\
\hline CV of WBC (\%) & 5.33 & & 7.78 & \\
\hline Neutrophil $\left(\times 10^{4} / \mathrm{mm}^{3}\right)$ & $1.82 \pm 0.10^{\mathrm{c}}$ & $1.71-1.94$ & $2.03 \pm 0.16^{\mathrm{b}}$ & $1.83-2.22$ \\
\hline Monnocyte $\left(\times 10^{4} / \mathrm{mm}^{3}\right)$ & $5.11 \pm 0.27^{\mathrm{d}}$ & $4.79-5.46$ & $6.09 \pm 0.47^{\mathrm{c}}$ & $5.51-6.67$ \\
\hline Large lymphocyte $\left(\times 10^{4} / \mathrm{mm}^{3}\right)$ & $0.60 \pm 0.03^{\mathrm{a} *}$ & $0.56-0.64$ & $0.77 \pm 0.06^{\mathrm{a} *}$ & $0.70-0.84$ \\
\hline Small lymphocyte $\left(\times 10^{4} / \mathrm{mm}^{3}\right)$ & $1.31 \pm 0.07^{b *}$ & $1.23-1.40$ & $1.67 \pm 0.13^{\mathrm{b} *}$ & $1.51-1.83$ \\
\hline $\mathrm{TC}\left(\times 10^{4} / \mathrm{mm}^{3}\right)$ & $4.36 \pm 0.23^{*}$ & $4.09-4.65$ & $3.40 \pm 0.27^{*}$ & $3.08-3.73$ \\
\hline CV of TC $(\%)$ & 5.28 & & 7.94 & \\
\hline
\end{tabular}

2 Notes: Each data point represents the mean of three replicates \pm SD and the range. *indicates

3 significant differences in blood cell counts and haematological parameters between males and

4 females $(\mathrm{P}<0.05)$; different letters $(\mathrm{a}, \mathrm{b}, \mathrm{c}, \mathrm{d})$ in the same column indicate significant differences

5 between leukoyte types $(\mathrm{P}<0.05)$. Coefficient of Variation $(\mathrm{CV})(\%)=($ Standard Deviation $/$

6 Mean) $\times 100 \%$. TBC: total blood cell counts. 


\section{Table 2(on next page)}

The size of the peripheral blood cells in argus snakehead (Mean $\pm S D, \mu m, N=20$ ).

** indicates that extremely significant differences between males and females $(P<0.01)$;

different letters $(a, b, c, d)$ in the same column indicate significant differences among different cells $(P<0.05)$. 
1 Table 2: The size of the peripheral blood cells in argus snakehead (Mean $\pm \mathrm{SD}, \boldsymbol{\mu m}, \mathbf{N}=\mathbf{2 0}$ ).

\begin{tabular}{|c|c|c|c|c|}
\hline \multirow[t]{2}{*}{ Cell types } & \multicolumn{2}{|c|}{ Females } & \multicolumn{2}{|c|}{ Males } \\
\hline & Cell length & Cell width & Cell length & Cell width \\
\hline Erythrocytes & $14.33 \pm 1.16^{* *}$ & $10.43 \pm 1.05$ & $13.11 \pm 0.88$ & $10.47 \pm 0.98$ \\
\hline (nuclei) & $\left(8.71 \pm 0.88^{* *}\right)$ & $(4.60 \pm 0.70 * *)$ & $(7.21 \pm 0.90)$ & $(3.55 \pm 0.79)$ \\
\hline Neutrophils & $16.64 \pm 2.16^{\mathrm{c}}$ & $14.83 \pm 2.45^{\mathrm{c}}$ & $15.21 \pm 2.21^{\mathrm{c}}$ & $13.55 \pm 2.16^{c}$ \\
\hline Monocytes & $16.60 \pm 1.77^{c}$ & $14.61 \pm 1.43^{c}$ & $15.51 \pm 1.34^{\mathrm{c}}$ & $14.29 \pm 1.10^{\mathrm{c}}$ \\
\hline Large lymphocytes & $11.38 \pm 2.67^{\mathrm{b}}$ & $9.92 \pm 2.50^{\mathrm{b}}$ & $11.94 \pm 2.17^{\mathrm{b}}$ & $10.31 \pm 2.09^{b}$ \\
\hline Small lymphocytes & $6.75 \pm 1.36^{\mathrm{a}}$ & $6.00 \pm 1.30^{\mathrm{a}}$ & $6.77 \pm 1.13^{\mathrm{a}}$ & $6.17 \pm 1.06^{\mathrm{a}}$ \\
\hline Thrombocytes & $19.18 \pm 3.19^{d}$ & $6.99 \pm 0.74^{\mathrm{a}}$ & $14.70 \pm 2.50^{\mathrm{c}}$ & $6.87 \pm 1.03^{\mathrm{a}}$ \\
\hline
\end{tabular}

2 Notes: ** indicates that extremely significant differences between males and females $(\mathrm{P}<0.01)$;

3 different letters $(\mathrm{a}, \mathrm{b}, \mathrm{c}, \mathrm{d})$ in the same column indicate significant differences among different

4 cells $(\mathrm{P}<0.05)$. 


\section{Table 3(on next page)}

Cytochemical staining patterns of peripheral blood cells in argus snakehead.

"+ + +" strongly positive; "+ +" positive;"+" weakly positive;"-" negative. 
1 Table 3: Cytochemical staining patterns of peripheral blood cells in argus snakehead.

\begin{tabular}{lccccccc}
\hline Cell types & POX & SBB & PAS & ACP & ALP & AS-D & $\alpha-N A E$ \\
\hline Erythrocytes & - & - & ++ & - & - & - & - \\
Neutrophils & +++ & +++ & ++ & +++ & + & ++ & + \\
Monocytes & - & - & ++ & + & - & + & ++ \\
Large lymphocytes & - & - & ++ & - & + & + & + \\
Small lymphocytes & - & - & ++ & - & - & + & + \\
Thrombocytes & - & - & ++ & + & - & + & \\
\hline
\end{tabular}

2 Notes: "+ + +" strongly positive; "+ +" positive;"+" weakly positive;"-" negative. 


\section{Table 4 (on next page)}

The values of RBC, Erythrocyte sizes, $\mathrm{Hb}, \mathrm{HCT}$ and MCV in argus snakehead and some other fish species.

The values of RBC, Erythrocyte sizes, Hb, HCT and MCV in argus snakehead were compared with those of some other fish. 
1 Table 4: The values of RBC, Erythrocyte sizes, Hb, HCT and MCV in argus snakehead and some other fish species.

\begin{tabular}{|c|c|c|c|c|c|c|}
\hline Species & $\operatorname{RBC}\left(10^{6} / \mathrm{mm}^{3}\right)$ & Erythrocyte sizes $(\mu \mathrm{m})$ & $\mathrm{Hb}(\mathrm{g} / \mathrm{dl})$ & НCТ(\%) & $\operatorname{MCV}(\mathbf{f l})$ & References \\
\hline Ophiocephalus argus & $2.72-3.30$ & $14.33 \pm 1.16 \times 10.43 \pm 1.05$ & $10.30-11.0$ & $41.52-45.66$ & $125.83-167.87$ & This study \\
\hline Lutjanus guttatus & $0.75-3.71$ & $11.04 \pm 0.85(10-13)$ & $7.29-17.03$ & $33.53-71.14$ & $135.66-369.80$ & Rio-Zaragoza et al. (2011) \\
\hline Cichlasoma dimerus & $1.68-4.27$ & $9.4-10 \times 6.2-7.3$ & $5.23-8.33$ & $22.5-39.12$ & $70.14-198$ & Vázquez and Guerrero (2007) \\
\hline Acipenser persicus & $4.8-7.9$ & & $8.60-9.87$ & $29.58-31.72$ & $412.20-621.70$ & Milad et al. (2016) \\
\hline Sorubim cuspicaudus & $3.5-14.0$ & $10.5 \times 8.8$ & $10.5 \pm 2.3$ & $25.5 \pm 5.6$ & & Negrete et al. (2010) \\
\hline Betta splendens & $1.70-2.21$ & $10.12-15.26 \times 7.37-12.59$ & $7.1-9.4$ & $31-39$ & $187.28 \pm 7.05$ & Motlagh et al. (2012) \\
\hline Horabagrus brachysoma & $1.66-2.43$ & & $7.2-9.9$ & $21.40-55.61$ & $88.07-335.0$ & Prasad and Charles (2010) \\
\hline Gymnocypris eckloni & $1.49-1.78$ & $14.88 \pm 0.76 \times 10.02 \pm 0.42$ & $5.21-7.93$ & $22.42-36.92$ & $150.98-207.42$ & Tang et al. (2015) \\
\hline Acipenser sinensis & $0.85 \pm 0.10$ & $17.98 \pm 0.96 \times 12.65 \pm 0.87$ & & & & Gao et al. (2007) \\
\hline Ctenopharyngodon idella & $1.76 \pm 0.23$ & $12.31 \pm 0.78 \times 8.27 \pm 0.72$ & & & $4.08 \pm 0.12$ & \\
\hline Megalobrama & $1.53 \pm 0.12$ & $13.61 \pm 0.85 \times 7.47 \pm 0.55$ & & & $3.06 \pm 0.10$ & Chen et al. (2019a) \\
\hline $\begin{array}{l}\text { amblycephala } \\
\text { Pelteobagrus fulvidraco }\end{array}$ & $1.41 \pm 0.10$ & $12.22 \pm 0.92 \times 9.98 \pm 0.83$ & & & $3.02 \pm 1.14$ & \\
\hline Glyptosternum maculatum & & $19.39 \pm 2.48 \times 15.15 \pm 1.91$ & & & & Zhang et al. (2011) \\
\hline
\end{tabular}

2 Notes: RBC: red blood cell counts; Hb: hemoglobin; HCT: hematoceit; MCV: mean corpuscular volume. 


\section{Figure 1}

Microstructure of peripheral blood cells in argus snakehead (Wright's staining).

(A) mature erythrocyte (arrow) : oval with a long oval nucleus; immature erythrocyte (arrowhead) : round, with a round nucleus. (B) neutrophil: globular with a bilobate nucleus, pale blue cytoplasm contained many tiny mauve and reddish particles. (C) neutrophil: round, with an eccentric and oval shape nucleus, cytoplasm contained a large number of fine light purple particles and vacuoles of different sizes. (D) monocyte: oval with a horseshoe-shaped nucleus, cytoplasm contained many small vacuoles. (E) large lymphocyte: round or irregularly round, with many projections on the surface. (F) small lymphocyte: elliptic, with minimal cytoplasm, and some microvilli protuberances at the margin. $(G)$ thrombocyte: spindle-shaped with an oval and mostly centered nucleus. $(\mathrm{H})$ thrombocyte: round with flocculent cytoplasm, often appeared in clusters with multiple cells. Scale bars $=10 \mu \mathrm{m}$. The magnification is $1000 \mathrm{X}$.
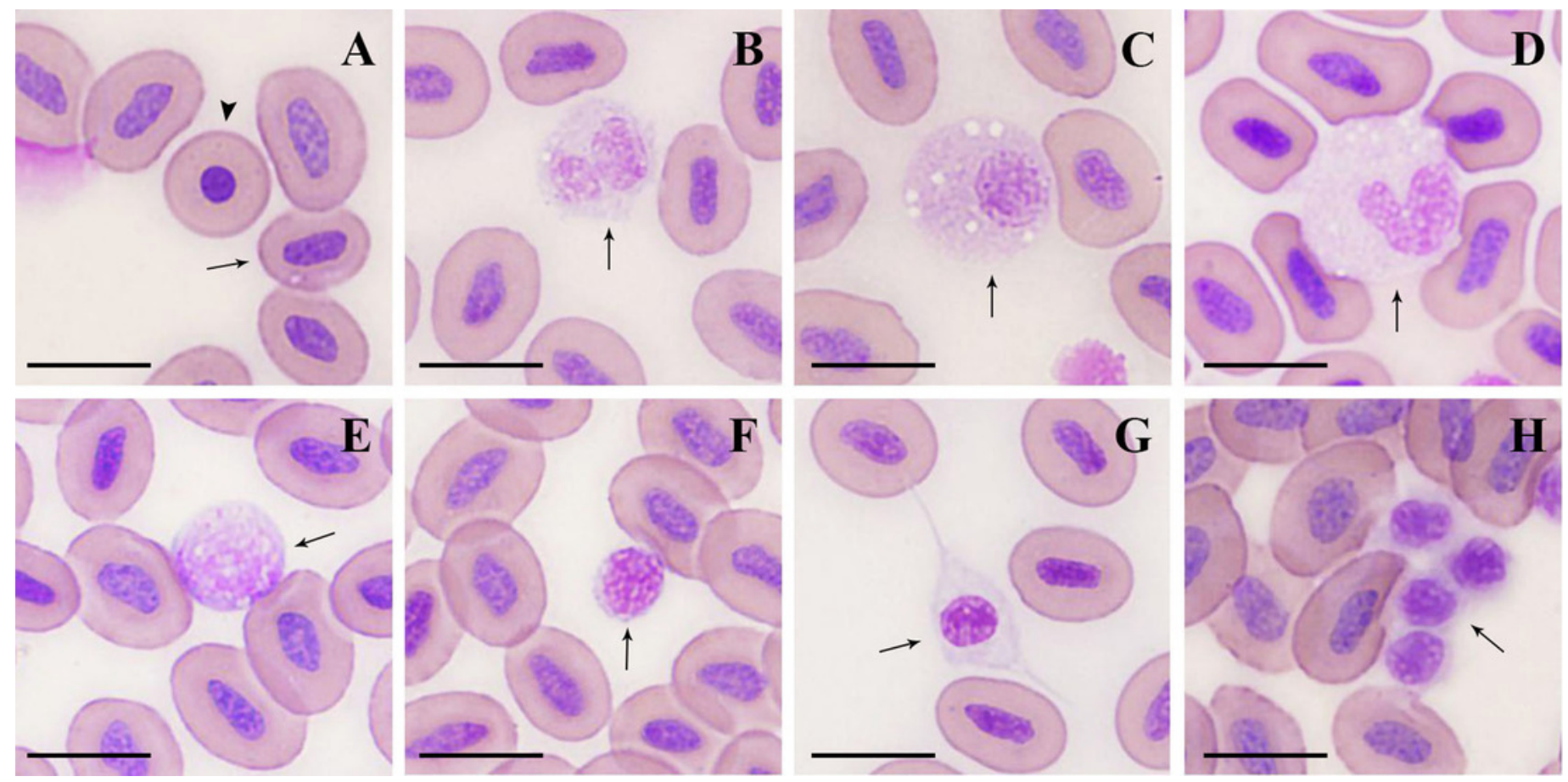


\section{Figure 2}

Cytochemical staining of peripheral blood cells in argus snakehead.

Erythrocytes were positive for PAS (CC), and negative for POX, SBB, ACP, ALP, AS-D and $\alpha$ NAE staining ( $A A, B B, D D, E E, F F, G G$ ); neutrophils exhibited strongly positive rection for POX, SBB and ACP (AB, BC, DE), positive for PAS and AS-D (CD, FG), and weakly positive for ALP and $\alpha-N A E$ staining $(E F, G H)$; monocytes showed positive for PAS and $\alpha-N A E(C E, G I)$, and weakly positive for ACP and AS-D (DF, FH), while negative for POX, SBB and ALP staining (AC, $B D, E G)$; large lymphocytes exhibited positive for PAS (CF), and weakly positive for ALP, AS-D and $\alpha-N A E(E H, F I, G J)$, while negative for POX, SBB and ACP staining (AD, BE, DG); small lymphocytes were positive for PAS (CG), and weakly positive for AS-D and $\alpha$-NAE (FJ, GK), while negative for POX, SBB, ACP and ALP staining (AE, BF, DH, EI); thrombocytes showed positive rection for PAS (CH), and weakly positive for ACP and AS-D (DI, FK), while negative for POX, SBB, ALP and $\alpha-N A E$ staining (AF, BG, EJ, GL). Scale bars $=10 \mu \mathrm{m}$. The magnification is $1000 x$. 


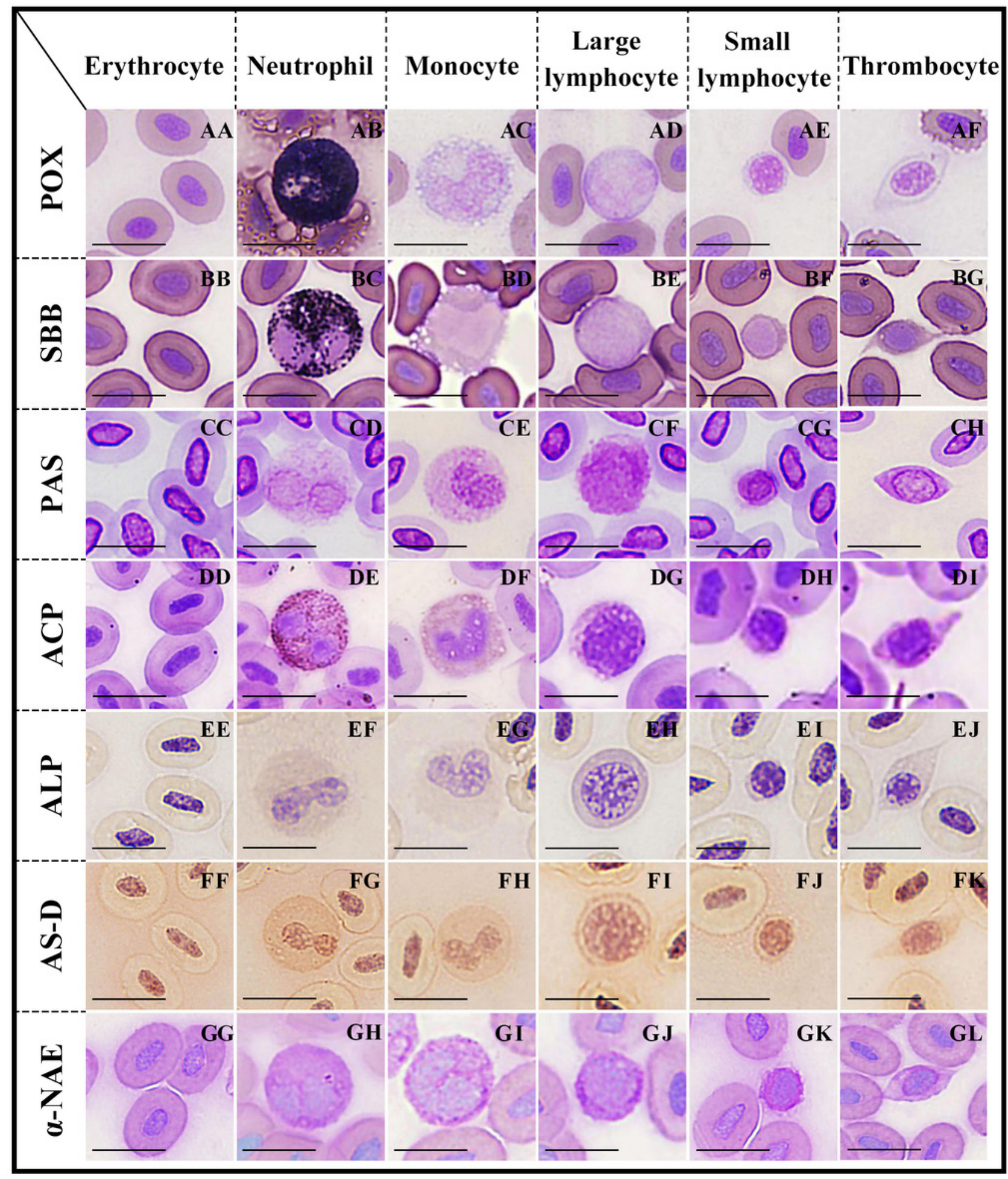

